\section{Confronting Hysteria: A Reply to Fairman and Curtiss To the Editor:}

In the March 2008 issue of JMCP, ${ }^{1}$ Fairman and Curtiss strongly criticized our controlled evaluation of a value-based insurance design (VBID) initiative published in the January 2008 issue of Health Affairs. ${ }^{2}$ More broadly, they take issue with the concept of VBID itself. Given the tone, we felt compelled to reply, yet disagree with only a few points of their critique. Before delving into the specifics, however, it is important to note that there is nothing included in their commentary that renders incorrect our findings that a reduction in out-of-pocket costs for patients significantly improved chronic medication adherence. More importantly, despite their critical assessment, we continue to believe that most health care stakeholders-including managed care pharmacists-will support our premise that it is not advisable to place strong financial disincentives on the use of high valued pharmacy and medical services.

Fairman and Curtiss raised 3 main criticisms. First, they claimed the results of studies such as ours are misinterpreted by the media and the concept of VBID is oversold. Second, they contend that the publication reports insufficient data to assess the validity of the findings (yet they do not fundamentally dispute the merits of the research design or the substance of the results). Last, they imply that the VBID concept is a bad idea. This third point may be an overstatement, but given the tone of the critique ("horrible surprises being designed to test your bravery and intellect"), we believe this is a reasonable interpretation of their position.

On the first point, we completely agree and sympathize with the viewpoint that VBID is often oversold, especially when it comes to the financial implications. Of particular concern are statements in the press-inaccurately attributed to us in the commentary - that VBID will reduce health care costs. A review on this topic would quickly reveal that we do not claim that this type of VBID program would save money. For example, we wrote in a recent commentary, "In a VBID implementation that only provides copay relief [as was the Health Affairs evaluation ${ }^{2}$ ], the employer expenditure will often exceed the aggregate costs." 3 This and other articles clearly articulate that the financial impact of VBID programs depends on the specific program design and the extent the intervention can target services to high risk patients with low baseline utilization.

Perhaps the confusion is in the subtle point that savings associated with increased use of high value services may exist, but may not outweigh the costs of the actual VBID program. As the authors note, and as we explicitly state in the Health Affairs article, ${ }^{2}$ we do not assess the financial effects of the intervention-a separate manuscript addressing expenditures is in progress. The closest we come to claiming anything about the financial effects is noting that preliminary analysis suggests the savings in nondrug services could offset the financial costs of increased use. We feel the commentary dramatically overstated our position in this study or elsewhere. At every opportunity, we stress that VBID can improve health outcomes per dollar spent at any level of health care expenditure, and refute claims of savings. ${ }^{4}$ It is our explicit intent to change the dialogue from one aimed at reducing expenditures, to a discussion directed at how we should finance health. We have testified on this precise point to federal commissions and include this conservative tone in our standard presentations. Thus, we welcome the authors' scrutiny of this common assertion of cost reduction, and would like to emphasize that we concur.

With regards to the study design and presentation, the most important issue, as Fairman and Curtiss note, is the validity of the control group. They make a minor flaw by suggesting that the critical question is whether the control group would have responded similarly to the intervention group. Instead, what matters is whether, in the absence of the intervention, the trend in the intervention group would have matched what was observed in the control group. We too would be more comfortable with this assumption if the groups were equivalent. Yet as we note in the manuscript, the groups differ. More important than additional details about the differences between groups, it is clear from the text and the figure that adherence varied at baseline.

While this feature appears troubling, several facts mitigate concern. First, in our study design, differences in baseline adherence are not a problem if trends are similar, which was the case. Second, adherence in the control group was generally stable. Our results were driven by adherence changes in the intervention group, as opposed to changes in the controls.

Fairman and Curtiss also contend that we do not describe the intervention in adequate detail, although most of that criticism was about missing details of the control-not interventiongroup. In addition to the description provided, we added that that implementation was imperfect (which we adjusted for in the computation of elasticities). Providing the requested details, (e.g., average copay for the treatment group [fell from about $\$ 20$ to about \$13] or benefit design in the control firm [which was complicated because of differences between mail order and retail charges and the blended use of copayments and coinsurance]) would not change the results. To reiterate, the most important element of our study design was that benefit design and chronic disease management_critical elements of utilization often not addressed in the existing literature-were stable in the control firm.

In some instances there were likely misunderstandings. For example, our pre-post adherence curves for both the treatment and control groups reflected our design which requalified subjects to maintain consistency in the pre and post samples (a goal we think we reasonably accomplished, as evidenced by the similar adherence in the control firm pre and post intervention). A single cohort design, as suggested by Fairman and Curtiss would be subject to bias (that would also need slaying), because adherence declines over time making the pre-post comparisons invalid. 
Other concerns raised, though not technically incorrect, fail to take into account the totality of the arguments. For example, we stated that the changes in medication adherence from copay lowering and copay increasing were likely symmetric. This conclusion was based on 2 pieces of evidence. First, the elasticities that we obtained were consistent with those found in a systematic review of a vast body of other literature focused on copay increases. ${ }^{6}$ Second, we cited work by Landon et al., which reported symmetry in the effects on spending from copay lowering and copay raising. ${ }^{7}$ Admittedly this was not adherence, but before the Health Affairs publication, ${ }^{2}$ there were no published controlled studies on copay lowering and adherence effects. We believe it is reasonable to expect symmetry in utilization if one finds symmetry in spending, since spending is determined by price and utilization. Unless there were strong price effects (which would be unlikely), our conclusion would hold.

The most serious critiques, related to generalizability, were clearly recognized and addressed in the Health Affairs article. As journal editors ourselves, we realize that the design used, like any design, cannot be definitive. Fairman and Curtiss are correct to bring to light these limitations, but they seem to be under the illusion that every study must eliminate all sources of bias. This is certainly not the case of papers published in JMCP, The American Journal of Managed Care, or any other journal. Our view is that each study is a contribution of an evolving body of evidence. This publication was unique in that it explicitly controlled for variation in disease management initiatives, a feature we consider of first order importance because it causally relates to medication adherence. Moreover, unlike several seminal studies in the adherence literature, it incorporated a fixed effects design. Many of its flaws, such as imprecision about the details of the control group formulary, could easily be applied to studies based on large claims datasets. ${ }^{5}$ The criticism seems to be focused on issues which, though potentially important, do not immediately suggest any particular biases in the findings or change in the main interpretation of the results.

Most importantly, Fairman and Curtiss seem to take fundamental issue with the concept of VBID. In this regard, we would be interested in their response to the following statements:

1) The utilization of maintenance medications for chronic disease is not responsive to copay changes. This is a difficult statement to agree with, because abundant and growing evidence (including research recently published in $J M C P^{8}$ ), suggests that these high valued pharmacy services are responsive to out-of-pocket costs. ${ }^{6,9}$

2) The utilization of maintenance medications for chronic disease is not important. Again we consider this a difficult position to agree with, because most clinical evidence supports use of maintenance medications in the clinical conditions we studied. Most evidence-based guidelines and quality improvement programs strongly advocate their increased use. Given the clinical data available, it is hard to dispute that use of these medications improves health and therefore, likely reduce adverse events. Whether the medical and non-medical financial offsets associated with enhanced use of chronic medications will counterbalance the extra spending, is an empirical question that deserves much more rigorous evaluation. No advocate for VBID or value in general, would argue that medical services-either high or low value-should be purchased in an inefficient manner, or that pharmacy benefit plans be designed without appropriate positive and negative incentives.

If Fairman and Curtiss disagree with both of the above statements then we proudly count them as supporters of VBID. It may be the case that though they support the VBID principles, they take issue with the feasibility or precise features of a VBID program, which is certainly reasonable. However, as our study and numerous ongoing initiatives demonstrate, "clinically sensitive" VBID programs can be implemented. It may also be the case that they believe that VBID is only a part of thoughtful benefit redesign and that it is unwise to expect copay relief to solve the health care cost problem or broader dysfunctions in the health care system. We could not agree more; we consider it preposterous for these authors to insinuate that we believe that VBID would "save the world." We have written extensively that VBID should not be viewed as a panacea for our system's ills, but that "restoring health to the health care cost debate" is merely a small step in the right direction.

Even if VBID is not the "dragon slayer" the authors refer to, we wish to reiterate that we unconditionally oppose the establishment of high out-of-pocket financial barriers for essential medications that clinicians "beg" their patients to take. We feel that managed care pharmacists-key stakeholders in the reform debate-would support this view; the proliferation of VBID products offered by pharmacy benefit managers bear this out. If Fairman and Curtiss defend the creation of patient-level barriers that will impede access to these high value services and ultimately worsen patient health, we are happy to take the alternative position. Our message is clear: cost-sharing is an important and essential part of an efficient health care system, yet it must be clinically derived in order to mitigate the adverse health care consequences associated with cost-related decreases in utilization. Available evidence allows us to depart the archaic "one-size-fits-all" approach to raising copayments for all services equally, and instead put our money where the health is. VBID plans, though by no means perfect, can support cost containment efforts and simultaneously enhance health While the adoption of VBID may not dress the emperor in royal vestments, we believe it will improve upon the tattered garments in which our health system is currently clothed.

Michael E. Chernew, PhD

Harvard Medical School

Chernew@hcp.med.harvard.edu 
Mayur R. Shah, MA

ActiveHealth Management*

unbounded@gmail.com

Arnold Wegh, MS

ActiveHealth Management

awegh@activehealth.net

Stephen N. Rosenberg, MD, MPH

ActiveHealth Management

srosenberg@activehealth.net

Iver A. Juster, MD

ActiveHealth Management

IJuster@activehealth.net

Allison B. Rosen, MD, ScD

University of Michigan School of Medicine

abrosen@umich.edu

\section{A. Mark Fendrick, MD \\ University of Michigan School of Medicine \\ amfen@umich.edu}

* affiliation when research was conducted

\section{DISCLOSURES}

Michael Chernew and Mark Fendrick provide consulting services to Hewitt Associates LLC and ActiveHealth Management related to value-based insurance design, and accept consulting fees and speaking honoraria related to value-based insurance design. Allison Rosen is employed by the University of Michigan's Center for Value-Based Insurance Design. Wegh, Rosenberg, and Juster are employed by ActiveHealth Management, which provides consulting services to employers, health plans, and pharmacy benefit managers. Shah is no longer affiliated with ActiveHealth Management. The study referred to in the JMCP editorial and this letter was supported by GlaxoSmithKline and Pfizer, and the Center for Value-Based Insurance Design lists 6 pharmaceutical manufacturers as supporters.

All authors were responsible for the study concept and design of this response to an editorial. All authors shared equally the data analysis, data interpretation, writing, and revision.

\section{REFERENCES}

1. Fairman KA, Curtiss FR. Making the world safe for evidence-based policy: Let's slay the biases in research on value-based insurance design. J Manag Care Pharm. 2008;14(2):198-204. Available at: www.amcp.org/data/ jmcp/JMCPMaga_March\%2008_198-204.pdf.

2. Chernew ME, Shah MR, Wegh A, et al. Impact of decreasing copayments on medication adherence within a disease management environment. Health Aff. 2008:27(1):103-12.

3. Fendrick AM, Chernew ME. Fiscally responsible, clinically sensitive cost sharing: contain costs while preserving quality. Am J Manag Care. 2007; 13(6pt2):325-27.

4. Fendrick, AM, Chernew, ME. Value-based insurance design: a clinically sensitive, fiscally responsible approach to mitigate the adverse clinical effects of high-deductible consumer-directed health plans. J Gen Int Med. 2007; 22:890-91.

5. Goldman DP, Joyce GF, Escarce JJ. Pharmacy benefits and the use of drugs by the chronically ill. JAMA. 2004;291(19):2344-50.

6. Gibson TB, Ozminkowski RJ, Goetzel RZ. The effects of prescription drug cost sharing: a review of the evidence. Am J Manag Care. 2005;11(11):730-40.
7. Landon BL, Rosenthal MB, Normand SLT. Incentive formularies and changes in prescription drug spending. Am J Manag Care. 2007; 13(6pt2):360-69.

8. Zhang D, Carlson A, Gleeson P, et al. Relationship of the Magnitude of Member Cost-Share and Medication Persistence With Newly Initiated Renin Angiotensin System Blockers. J Manag Care Pharm. 2007;13:664-76.

9. Goldman DP, Joyce GF, Zheng Y. Prescription drug cost sharing: associations with medication and medical utilization and spending and health. JAMA. 2007;298(1):61-69.

\section{The Editors Respond Regarding the Shortcomings in Reported Research on Value-Based Insurance Design}

We thank Chernew and colleagues for their response to our editorial on value-based insurance design (VBID) ${ }^{1}$ and for their stated commitment to health care system improvement. Of course, in making improvements to prescription drug benefit designs in an effort to improve compliance, the key question is not whether it is desirable to encourage patients to be adherent with chronic medication therapy; any reasonable observer would agree that patients should be encouraged to take medication as prescribed. The key questions are (1) whether the proposed benefit design change(s) improve compliance to a degree that affects patient outcomes, and (2) whether the additional expenditure associated with the change is efficient, that is, whether it allocates resources in a way that maximizes their value or wastes resources that could better be spent elsewhere. Put simply, the key question is what outcome(s) a health plan "buys" when it lowers copayments, thereby increasing its net cost for prescription drugs.

Unfortunately, no one really knows the answer to that question, and Chernew et al.'s work provides little, if any, of the needed insight. Like their original research article, ${ }^{2}$ their letter is regrettably more notable for what it omits than for what it says. Among the important issues raised by Fairman and Curtiss, but unaddressed by the authors' letter, are:

1) whether the medication possession ratio effect estimated by Chernew et al., an added 7 to 14 days of therapy annually, could reasonably be expected to have any impact on patient outcomes;

2) whether the study's results reflect selection bias associated with open enrollment, in which members with a choice of plan (e.g., spouse's insurance) who anticipate a high level of compliance with chronic medication use in the coming year naturally gravitate toward the plan in which drugs are available at a lower copayment;

3) what the actual total cost of the intervention was; and

4) whether key characteristics of the 2 employer plans and beneficiaries (e.g., formulary content, pharmacy benefit design features, industry sector, beneficiary-to-employee ratio, baseline expenditures, and levels of chronic disease) would have supported Chernew et al.'s view that their study results are valid and relevant to health plans making decisions about benefit designs, had these critical details been included in the Chernew et al. research report. 
While we do not oppose VBID in concept, we await the findings of research to determine its effectiveness, since to date controlled research evidence does not support it. As Fairman pointed out in her editorial review of cost-sharing in the January/ February 2008 issue of JMCP, the assertion that commercially insured beneficiaries are price-sensitive in adherence to chronic medications is based largely on studies with weak cross-sectional research designs. Controlled studies of typical copayment increase amounts in commercial populations have documented modest effects on utilization overall and little or no impact on adherence to chronic medication. ${ }^{3}$ We are aware of only 1 study of out-of-pocket (OOP) cost reduction and adherence prior to the Chernew et al. analysis. Using a quasi-experimental (pre-post with comparison group) design, that study found that providing free glucose test strips to patients with diabetes "shifted costs from patient to health plan, without improving adherence" in blood glucose monitoring. ${ }^{4}$

While we await studies of the effect of reducing copayments for brand drugs, payers can reduce patient OOP cost by promoting the use of generic medications. Generic drugs are available in most chronic therapeutic classes and in all the classes studied by Chernew et al. (except inhaled corticosteroids, for which there was no significant association between the benefit design and adherence), for a mean OOP cost of $\$ 11$ per prescription in nationwide employer-sponsored plans in $2006^{5}$ and $\$ 5$ per prescription in Chernew et al.'s intervention plan. ${ }^{2}$

We do not understand Chernew et al's assertion that our editorial inaccurately attributed to them statements made by others. Our editorial directly quoted Chernew et al.'s original research article and the press release put forth by the University of Michigan, which houses the Center for Value-Based Insurance Design., ${ }^{1,2,6}$ These quotations included Chernew et al.'s statements that "...we expect health improvements, although we do not quantify them in this study," and that because of the intervention, "there might be gains in worker productivity or reduced absenteeism or disability." 2 As we noted in our editorial, Chernew et al.'s report provided neither citations to published research nor study findings to support these statements. ${ }^{1}$ In that vein, we find it troubling that the University of Michigan's press release described the Chernew et al. analysis as a "rigorous, controlled trial," ${ }^{6}$ a term that erroneously implied randomization in an analysis that was in fact not randomized.

We are also disappointed by Chernew et al.'s persistent refusal to present critical data about their study groups, especially since, as we pointed out in our editorial, the small amount of information presented in the study report suggested that the study groups were very different at baseline (e.g., mean age difference of 7 years, baseline cost-sharing per generic claim of $\$ 5.00$ and $\$ 16.22$ for intervention and comparison groups, respectively).1,2 Whether the comparison group ("Company B" 6 ) is adequate to represent what the experience of a true control group would have been (i.e., had beneficiaries of "Company A" ${ }^{6}$ been randomized to intervention and control groups) remains unknown. Transparent disclosure of fundamental factors, such as the actual pharmacy benefit designs, formulary content, and baseline health-related information (e.g., utilization, chronic disease) for the 2 study groups would have enabled readers to decide for themselves whether the effects claimed for this VBID intervention are based on a valid analysis that provides relevant information for their health plans. As threats to the internal validity of trend analyses of non-randomized groups (e.g., possible selection bias associated with the intervention; the possibility of "selection maturation" effects that could be associated with different levels of chronic disease) are well known, ${ }^{7}$ we dispute Chernew et al.'s contention that their analyses are valid despite baseline differences, and we remain concerned about lack of disclosure. Chernew et al's dismissal of legitimate questions about the missing information with the statement that transparency "would not change the results" is both unhelpful and inconsistent with basic standards for the reporting of research results. ${ }^{8.9}$

The feedback that we have received from health plans in response to our editorial suggests widespread frustration regarding the abundance of hype without substance regarding VBID. Mindful of what Chernew et al. describe as a "proliferation of VBID products," we continue to urge both the conduct of bettercontrolled studies of cost-sharing decreases and appropriate caution in the adoption of untested benefit designs described as innovations.

\section{Kathleen A. Fairman, MA}

JMCP Associate Editor and Senior Methodology Reviewer kathleenfairman@qwest.net

\author{
Fredric R. Curtiss, PhD, RPh, CEBS \\ JMCP Editor-in-Chief \\ fcurtiss@amcp.org
}

\section{DISCLOSURES}

The editors report no conflict of interest on this subject.

\section{REFERENCES}

1. Fairman KA, Curtiss FR. Making the world safe for evidence-based policy: Let's slay the biases in research on value-based insurance design. J Manag Care Pharm. 2008;14(2):198-204. Available at: www.amcp.org/data/ jmcp/JMCPMaga_March\%2008_198-204.pdf

2. Chernew ME, Shah MR, Wegh A, et al. Impact of decreasing copayments on medication adherence within a disease management environment. Health Aff. 2008;27(1):103-12.

3. Fairman KA. The future of prescription drug cost-sharing: real progress or dropped opportunity? J Manag Care Pharm. 2008;14(1):70-82. Available at: www.amcp.org/data/jmcp/JMCPMaga_JanFeb\%2008_070-082.pdf.

4. Karter AJ, Parker MM, Moffet HH, et al. Effect of cost-sharing changes on self-monitoring of blood glucose. Am J Manag Care. 2007;13(7):408-16.

5. Kaiser Family Foundation. Prescription drug trends fact sheet: May 2007. Available at: www.kff.org/rxdrugs/3057.cfm. Accessed August 10, 2007. 
6. Department of Public Relations and Marketing Communications, University of Michigan. The co-pay connection: lowering drug co-pays for chronic disease patients increases use of important preventive medicines, rigorous study shows. UMHS Press Release. January 8, 2008. Available at: www.med.umich.edu/opm/newspage/2008/drugcopay.htm. Accessed January 26, 2008.

7. Cook TD, Campbell DT. Quasi-Experimentation: Design and Analysis Issues for Field Settings. Boston: Houghton Mifflin Company;1979.

8. Motheral B, Brooks J, Clark MA, et al. A checklist for retroactive database studies-Report of the ISPOR Task Force on Retrospective Databases. Value Health. 2003;6(2):90-97. Available at: www.ispor.org/workpaper/healthscience/ret_dbTFR0203.asp. Accessed March 20, 2008.
9. von Elm E, Altman DG, Egger M, Pocock SJ, Gøtzsche PC, Vandenbroucke JP; for the STROBE Initiative. The Strengthening the Reporting of Observational Studies in Epidemiology (STROBE) statement: guidelines for reporting observational studies. Ann Intern Med. 2007; 147(8):573-77. Available at: www.annals.org/cgi/content/full/147/8/573\#T1. Accessed March 21, 2008. 